\title{
A search for sex-specific antigens on bovine spermatozoa using immunological and biochemical techniques to compare the protein profiles of $X$ and $Y$ chromosome-bearing sperm populations separated by fluorescence-activated cell sorting
}

\author{
E. A. Howes ${ }^{1}$, N. G. A. Miller ${ }^{2}$, C. Dolby ${ }^{1}$, A. Hutchings ${ }^{2}$, \\ G. W. Butcher ${ }^{2}$ and R. Jones ${ }^{1}$ \\ ${ }^{1}$ Department of Signalling and ${ }^{2}$ Department of Immunology, The Babraham Institute, Babraham, \\ Cambridge CB2 4AT, UK
}

\begin{abstract}
Currently, the only successful method for separating $X$ and $Y$ chromosome-bearing spermatozoa is fluorescence-activated cell sorting. Although effective, this technique is of limited usefulness to the animal breeding industry as it cannot produce the large volumes of sexed spermatozoa needed for artificial insemination. An attractive alternative would be to identify an immunological marker confined to one sperm type and, therefore, significant scientific effort has been expended in examining antibodies that appear to recognize approximately $50 \%$ of spermatozoa in an ejaculate. However, no sex-specific antigens have yet been identified from spermatozoa. Using the opportunity afforded by the development of sperm separation by fluorescence-activated cell sorting, we have made a thorough search for differences between $X$ and $Y$ chromosome-bearing bull spermatozoa using both biochemical and immunological methods. Techniques for radiolabelling surface membrane proteins, in conjunction with SDS-PAGE, failed to show any differences between populations. Similarly, a wide range of monoclonal antibodies raised to ejaculated, cauda epididymidal and testicular spermatozoa failed to distinguish between the $X$ and $Y$ chromosome-bearing spermatozoa. Only after analysis by high resolution two-dimensional SDS-PAGE was an indication obtained that $X$-specific proteins occur. However, these proteins are not associated with the surface membrane and further work is necessary to confirm their association with the $X$ chromosome and to characterize them more fully. Our inability to detect sex-specific differences in sperm surface antigenicity suggests that further work on this immunological approach to semen sexing is unlikely to be profitable.
\end{abstract}

\section{Introduction}

A reliable method for controlling the sex of farm animals would have considerable impact on the efficiency of the animal breeding industry and, if applicable to humans, could also be used to reduce the incidence of sex-linked diseases. An obvious way of achieving this is to separate $X$ and $Y$ chromosomebearing spermatozoa before insemination. In the past, a number of methods for sperm separation have been devised based on supposed differences in density (Harvey, 1946), speed of swimming (Ericsson et al., 1973), surface charge characteristics (Kaneko et al., 1984), interaction with H-Y antibody (Goldberg et al., 1971) and staining response with quinacrine (Barlow and Vosa, 1970; Pearson and Bobrow, 1970). Thus, the procedure of allowing spermatozoa to distribute through a column of albumin, claimed to bias the outcome of pregnancy in humans, is based on a belief that $Y$ chromosome-bearing spermatozoa

Received 2 January 1997 are more motile than $\mathrm{X}$ chromosome-bearing spermatozoa (Beernink et al., 1993). However, the albumin technique, in common with other sperm separation methods based on apparent inequalities between $X$ and $Y$ chromosome-bearing spermatozoa, has produced equivocal results (reviewed in Windsor et al., 1993).

The only feature of mammalian spermatozoa currently accepted as differing consistently between the $X$ and $Y$ chromosome-bearing components of the population is DNA content. In mammals, the $\mathrm{X}$ chromosome is larger than the $\mathrm{Y}$ chromosome and hence contains more DNA. The degree of difference depends upon species and amounts to approximately $2.9 \%$ in human spermatozoa (Sumner and Robinson, 1976), approximately $3.8 \%$ in bulls and as much as about $7.5 \%$ in chinchilla (Johnson, 1992). This disparity in DNA content has been exploited to develop a successful method of sperm separation using flow cytometry. After exposure of spermatozoa to Hoechst 33342 , a fluorescent dye that binds stoichiometrically to DNA, two populations can be distinguished on 
the basis of their fluorescent characteristics, and these can be separated by fluorescence-activated cell sorting (FACS) using a modified flow cytometer (Johnson and Pinkel, 1986). In this way, spermatozoa from rabbits (Johnson et al., 1989), pigs (Johnson, 1992), bulls (Cran et al., 1993) and humans (Johnson et al., 1993) have been separated into $X$ and $Y$ chromosomebearing populations with an efficiency of between $70 \%$ and $90 \%$. The technique has been validated both by re-analysis of sorted spermatozoa (Johnson et al, 1989) and by sexing individual sorted spermatozoa by PCR (Welch et al., 1995) or in situ hybridization with $X$ or $Y$ chromosome-specific DNA probes (Johnson et al., 1993). In addition, fertilization trials with sorted spermatozoa in rabbits (Johnson et al., 1989) and cattle (Cran et al., 1993) have produced appropriately biased sex ratios and have also shown that separating spermatozoa by FACS does not adversely affect their fertilizing capacity or prevent normal embryonic development. A study in rabbits, however, suggested an increase in the number of fetuses lost during the early stages of pregnancy (McNutt and Johnson, 1996). The technique is regarded as suitable for use in humans and has been used in at least one clinical trial to prevent the possibility of X-linked hydrocephalus (Levinson et al., 1995).

Although clearly effective, the use of FACS as a routine tool for sex selection in animal breeding is limited by the low rate of sorting (about $0.5 \times 10^{6} \mathrm{~h}^{-1}$ ), which produces too few spermatozoa for standard artificial insemination $(\mathrm{AI})$ procedures and restricts its use to in vitro fertilization techniques. However, the use of FACS provides a new opportunity to investigate and compare separated populations of $X$ and $Y$ chromosomebearing spermatozoa for properties that might be of use in designing methods to separate large numbers of spermatozoa for AI. In this respect, the surface components of the two populations are of particular interest, since differences in membrane antigenicity could be exploited to generate antibodies capable of separating $\mathrm{X}$ or $\mathrm{Y}$ chromosome-bearing spermatozoa.

We have investigated the profile of antigens in both unsorted and FACS-sorted bovine spermatozoa using a variety of techniques including radiolabelling of surface membrane components, one- and two-dimensional gel electrophoresis of sperm proteins and reactivity with a large panel of polyclonal and monoclonal antibodies to sperm proteins. The aim has been to look for a consistent difference between $X$ and $Y$ chromosome-bearing spermatozoa that could form a reliable basis for developing immunological separation techniques.

\section{Materials and Methods}

\section{Chemicals}

All chemicals were of the highest purity commercially available and were obtained from Sigma Ltd (London), Pharmacia Biotech (St Albans, Herts) or BioRad Laboratories Ltd (Hemel Hempstead, Herts). Reagents for two-dimensional SDS-PAGE and 'Immobilon' blotting membrane were purchased from Millipore (UK) Ltd (Watford, Herts). Bolton and Hunter reagent and $\mathrm{Na}^{125}$ I were supplied by Amersham International (Little Chalfont, Bucks), Iodogen reagent by Pierce and Warriner (UK) Ltd (Chester, Cheshire).

\section{Collection and washing of semen}

Semen was collected using an artificial vagina from Holstein Friesian bulls of proven fertility. Care was taken to avoid exposing the semen to temperature changes during its transfer to the laboratory, which occurred within $1.5 \mathrm{~h}$ of collection. Semen was washed by diluting 1:1 with PBS and layering samples of about $3 \mathrm{ml}$ over a cushion of $0.25 \mathrm{~mol}$ sucrose $\mathrm{I}^{-1}$ in $10 \mathrm{mmol}$ Tris- $\mathrm{HCl} \mathrm{I}^{-1}, \mathrm{pH} \mathrm{7.4,} \mathrm{in} \mathrm{a} \mathrm{glass} \mathrm{centrifuge} \mathrm{tube.}$ The sample was centrifuged at $450 \mathrm{~g}$ for $10 \mathrm{~min}$ at room temperature and the supernatant aspirated to leave a loose pellet of spermatozoa. Seminal plasma adhering to the walls of the tube was wiped away with a tissue; the sperm pellet was resuspended in $9 \mathrm{ml} \mathrm{PBS}$, centrifuged as above and the pellet made up to a final volume of $1 \mathrm{ml}$ in PBS.

Testicular and epididymal spermatozoa were collected post mortem from bulls. The testes were transported to the laboratory within $2 \mathrm{~h}$ of removal and spermatozoa were flushed out of the cauda epididymidis with PBS. Testicular spermatozoa were collected by aspiration of testicular fluid from the rete testis. Cauda epididymidal spermatozoa, which were uncontaminated with other cell types, were diluted tenfold in PBS and washed twice by centrifugation as described above. Rete testis fluid, which contained variable amounts of red blood cells and ciliated epithelial cells, was layered over a three-step Percoll gradient $(20 \%, 40 \%, 60 \%)$ and centrifuged at $2000 \mathrm{~g}$ for $20 \mathrm{~min}$. Spermatozoa accumulating at the $40 \% / 60 \%$ interface were removed and washed once in PBS as described above.

\section{Separation of $X$ and $Y$ chromosome-bearing spermatozoa by fluorescence-activated cell sorting}

A washed sample of spermatozoa $\left(2 \times 10^{7} \mathrm{ml}^{-1}\right)$ was incubated with $10 \mu \mathrm{mol}$ Hoechst $33342 \mathrm{I}^{-1}$ for $\mathrm{I} \mathrm{h}$ at $35^{\circ} \mathrm{C}$. The stained spermatozoa were then passed through a fluorescence activated cell sorter (FACStar Plus; Becton Dickinson) fitted with an ultraviolet laser and with two photomultiplier tubes placed at right angles to detect sperm orientation, as described in Cran et al. (1993). The fluorescence signal from appropriately aligned spermatozoa was used to identify them as $X$ or $Y$ chromosome-bearing as they passed the $0^{\circ}$ detector and the cells were subsequently deflected into two separate sterile $2 \mathrm{ml}$ polypropylene tubes (Falcon 2063). The sorting rate was approximately $0.5 \times 10^{6}$ cells $\mathrm{h}^{-1}$ of each type. The introduction of extraneous proteins to the sperm surface was avoided by not using bovine serum albumin in the sheath fluid and not collecting the spermatozoa into egg yolk (standard procedure when collecting spermatozoa for fertilization) but to optimize recovery of sorted spermatozoa, tubes were pre-coated with $0.1 \%$ FCS in PBS, thoroughly rinsed with PBS and dried. At intervals during the sorting process, spermatozoa in the collecting tubes were concentrated by centrifugation since they were observed to become immobile at high dilutions.

\section{Examination of sperm surface proteins by one-dimensional SDS-PAGE}

The small number of spermatozoa derived from cell sorting precluded direct comparison of detergent-extracted proteins Downloaded from Bioscientifica.com at 04/26/2023 10:59:30AM 
from $X$ and $Y$ chromosome-separated populations by SDSPAGE, even using relatively sensitive silver staining techniques. Hence, surface membrane proteins were radiolabelled with ${ }^{125}[]$ to increase sensitivity of detection. For labelling surface proteins, samples of sorted ejaculated spermatozoa containing $2.5 \times 10^{6}$ cells were iodinated using either lodogen reagent (Markwell and Fox, 1978) or the lactoperoxidase technique (David and Reisfeld, 1974) using protocols described by Jones et al. (1983). Samples of unsorted spermatozoa $\left(3.5 \times 10^{8}\right.$ cells) from ejaculates and cauda epididymides were similarly treated. For comparative purposes, unsorted spermatozoa were also iodinated using Bolton and Hunter reagent (Bolton and Hunter, 1973) which iodinates a wider range of proteins than the other methods, but does not selectively label those at the cell surface. Proteins were extracted from the washed, radiolabelled sperm pellet by incubation for $4 \mathrm{~min}$ in $20 \mu \mathrm{l} 2 \%(\mathrm{w} / \mathrm{v})$ SDS in $62.5 \mathrm{mmol}$ Tris-HCl $1^{-1}, \mathrm{pH} 7.4$. Solubilized proteins were collected by centrifugation at $10000 \mathrm{~g}$ for $5 \mathrm{~min}$ and stored at $-20^{\circ} \mathrm{C}$. Accrued samples from four separate sorts, using material from three different bulls, were combined to give sufficient material to reach detection amounts. Proteins were precipitated with 9 volumes of ice-cold $100 \%$ ethanol for $30 \mathrm{~min}$, the pellets dried and solubilized by boiling in $100 \mu \mathrm{l} 2 \%$ SDS in $62.5 \mathrm{mmol}$ Tris- $\mathrm{HCl}$ $1^{-1}, \mathrm{pH} 7.4$ before being loaded on to $8.5-12.5 \%$ gradient gels to give 100000 c.p.m. in each well. After electrophoresis, gels were fixed ( $40 \%$ methanol, $7 \%$ acetic acid, $53 \%$ water), dried and radioactivity detected with Hyperfilm-MP (Amersham) at $-80^{\circ} \mathrm{C}$.

\section{Production of monoclonal antibodies}

Whole spermatozoa or membrane vesicles resuspended in PBS were emulsified with complete Freund's adjuvant and injected subcutaneously at multiple sites into female Lou/C rats (Harlan Olac, Bicester). A second injection of the antigen in incomplete Freund's adjuvant was given 30-40 days later. Preimmune and immune blood was collected from each rat.

Groups of three rats were immunized using a number of different protocols. These were: (1) washed, unsorted ejaculated spermatozoa in numbers ranging from $2.5 \times 10^{6}$ and $1 \times 10^{7}$ cells per rat; (2) X or $Y$ chromosome-enriched populations of ejaculated spermatozoa at $4 \times 10^{6}$ cells per rat; (3) an enriched sperm plasma membrane preparation obtained from ejaculated spermatozoa by vortexing (Jones, 1986); (4) as in groups 1-3 above using cauda epididymidal spermatozoa; (5) unsorted or FACS-sorted testicular spermatozoa; and (6) initial immunizations with unsorted cauda epididymidal or testicular spermatozoa, or with enriched plasma membrane preparations of cauda epididymidal spermatozoa, followed by a booster injection of sorted ejaculated spermatozoa.

Group 1 immunizations were designed to assess the numbers of spermatozoa needed to produce a strong immune reaction. Plasma membrane preparations were used in an attempt to target the production of antibodies to membraneassociated proteins; that is, those most likely to be of use for semen sexing, while spermatozoa from the testis and cauda epididymidis were used to avoid the highly antigenic seminal plasma proteins abundant on the surface of all ejaculated spermatozoa.
Animals showing a strong immune response (assessed using antisera to probe western blots of sperm proteins) were boosted by an intravenous injection of antigen, and 4 days later spleen cells were taken for fusion with either Y3Ag1.2.3 (Galfre et al., 1979) or IR983F (Bazin, 1982) rat myeloma cells, as described by Galfre and Milstein (1981). Supernatants from the resulting hybridomas were screened by western blotting and by indirect immunofluorescence (IIF) on smears of testicular, epididymidal and ejaculated spermatozoa. Antibodies of interest were cloned from single cells using the limiting dilution technique.

\section{Screening of antisera and hybridoma supernatants}

Antisera and supernatants were screened on western blots (Jones, 1986) containing detergent-extracted proteins $(1 \%(\mathrm{v} / \mathrm{v})$ Nonidet P-40 (NP40) in $50 \mathrm{mmol}$ Tris- $\mathrm{HCl} \mathrm{l}^{-1}, \mathrm{pH} \mathrm{7.4}$, for $30 \mathrm{~min}$ at $4^{\circ} \mathrm{C}$ ) from ejaculated or cauda epididymidal spermatozoa separated by SDS-PAGE (Laemmli, 1970). Where appropriate, gels were stained with 5\% (w/v) Coomassie blue R-250 in methanol: acetic acid: water (40:7:53). Protein concentrations were measured by absorbance at $280 \mathrm{~nm}\left(\mathrm{E}_{280}\right.$ of 1.0 taken as equivalent to $1 \mathrm{mg} \mathrm{ml}^{-1}$ ) or colorimetrically by dye-binding (Bradford, 1976) using BSA as standard. In addition, all supernatants, irrespective of their reactivity on western blots, were screened by indirect immunofluorescence (Gaunt et al., 1983) on air-dried smears of unsorted or sorted spermatozoa. Where appropriate, additional checks were made using washed, intact spermatozoa labelled in suspension. The cellular location of antibody binding and the percentage of fluorescent spermatozoa were calculated from counts of 300 cells.

\section{High resolution two-dimensional SDS-PAGE}

Sperm samples of very high purity separated by FACS were obtained by reducing the width of the sort gates (see Fig. 1b) to collect only from the extreme edges of the population. Although this restricted the rate at which spermatozoa could be accumulated, it increased the purity of the samples to about $80 \%$. In three separate experiments, sperm samples from 12-19 individual sorts of 1 day duration were pooled to give sufficient material for two-dimensional SDS-PAGE analysis. In one of these experiments semen from three different bulls was used, while in the other two experiments the pooled samples were from a single bull but from a different individual in each case. Each sorted sperm sample was transferred to an Eppendorf tube and centrifuged at $9000 \mathrm{~g}$ for $10 \mathrm{~min}$, the supernatant was removed and the sperm pellet frozen at $-20^{\circ} \mathrm{C}$. When sufficient material had been accumulated for each experiment, the samples were pooled into a total volume of $20 \mu \mathrm{l}$ of lysis buffer (9 mol urea $\mathrm{l}^{-1}, 2 \%(\mathrm{w} / \mathrm{v})$ NP40, $20 \mathrm{mmol}$ DTT $\mathrm{I}^{-1}$ ) for $\mathrm{Ih}$ at room temperature. The lysate was then centrifuged at $9000 \mathrm{~g}$ for $10 \mathrm{~min}$ and the supernatant retained on ice until loaded onto the isoelectric focusing (IEF) gel.

Two-dimensional SDS-PAGE was carried out using the Millipore Investigator ${ }^{(*)}$ system following the manufacturer's instructions. Briefly, for IEF a mixture of broad range ( $\mathrm{pH} 3-10)$ and narrow range ( $\mathrm{pH} 4-8)$ ampholytes was included in a gel solution containing $9.5 \mathrm{~mol}$ urea $\mathrm{I}^{-1}, 2 \% \mathrm{NP} 40$, 
(a)
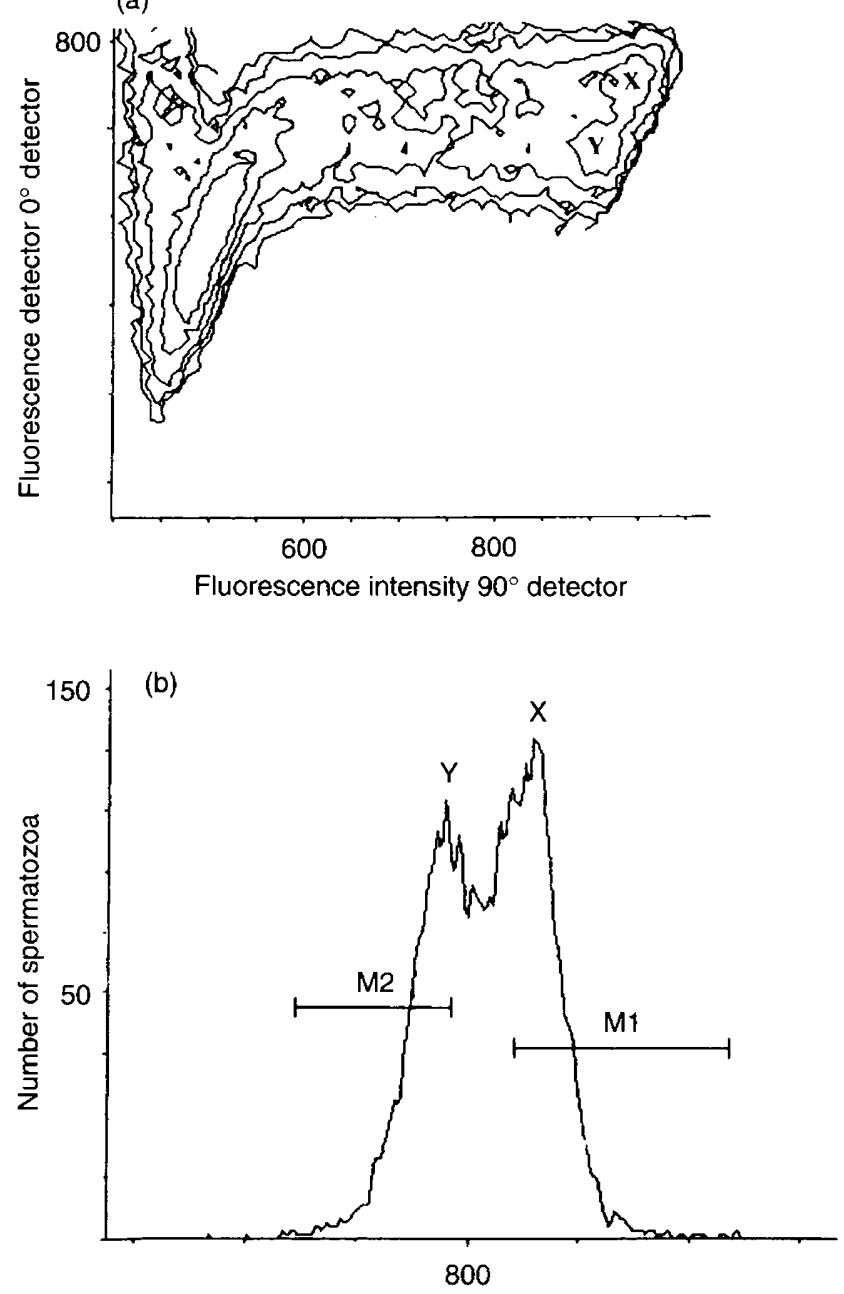

Fluorescence intensity $0^{\circ}$ detector

Fig. 1. Identification and separation of $X$ and $Y$ chromosome-bearing spermatozoa from a bovine ejaculate. (a) Two-dimensional plot of fluorescence monitored by $90^{\circ}$ and the $0^{\circ}$ detectors, showing the appearance of two peaks within the high fluorescence region of the $90^{\circ}$ detector. The lower peak is characteristic of $Y$ chromosomebearing spermatozoa aligned edge on to the $90^{\circ}$ detector, while the upper peak derives from $X$ chromosome-bearing spermatozoa. (b) Histogram of these two peaks showing the degree of overlap between the two populations and the positions of the sort gates (M1 for X-bearing and $\mathrm{M} 2$ for $\mathrm{Y}$-bearing spermatozoa) controlling the regions of selection within the peaks.

4.1\% acrylamide and 5 mmol CHAPS $1^{-1}$ cast in pre-threaded tubes (internal diameter, $\mathrm{I} \mathrm{mm}$ ). The tubes in the firstdimension running tank were positioned vertically with the lower end in anode buffer ( $100 \mathrm{mmol}$ phosphoric acid $\left.\mathrm{l}^{-1}\right)$ and the upper in cathode buffer ( $100 \mathrm{mmol} \mathrm{NaOH} \mathrm{^{-1 }}$ ). After prefocusing for $90 \mathrm{~min}$, samples were injected on to the gel surface on the cathode side. Extracts from $X$ and $Y$ chromosome-bearing samples were run in parallel and all samples were run under identical conditions (18 000 Volthours: $17 \mathrm{~h}$ at $1000 \mathrm{~V}, 0.5 \mathrm{~h}$ at $2000 \mathrm{~V}$ ) so that gels would be comparable. The focused tube gels were extruded into $5 \mathrm{ml}$ gel equilibration buffer $\left(0.3 \mathrm{~mol}\right.$ Tris base $\mathrm{I}^{-1}, 0.075 \mathrm{~mol}$ Tris-HCl $1^{-1}, 3 \%(\mathrm{w} / \mathrm{v}) \mathrm{SDS}, 50 \mathrm{mmol}$ DTT $\mathrm{l}^{-1}$ and $0.01 \%(\mathrm{w} / \mathrm{v})$ bromophenol blue), incubated at room temperature for $2 \mathrm{~min}$ and transferred to the top of the second dimension gels. These were slab gels $(230 \mathrm{~mm} \times 220 \mathrm{~mm} \times 1 \mathrm{~mm})$ designed to give maximum resolution of proteins and were cast using Duracryl (Millipore), a high tensile strength acrylamide, at a final concentration of $12.5 \%$. Gels were subjected to electrophoresis together in a temperature-controlled tank at $20^{\circ} \mathrm{C}$ for $5-8 \mathrm{~h}$ at $16000 \mathrm{~mW}$ per gel. Gels were silver stained according to the protocol recommended by Millipore based on the technique of Morrissey (1981). The positions of all resolved proteins were marked on transparent overlays and these were used to compare the distribution of proteins between gels. Gels were calibrated using two-dimensional SDS-PAGE protein standards (Bio-Rad; pI range 4.5-8.5, molecular mass $76-17.5 \mathrm{kDa}$ ).

\section{Results}

\section{Efficiency of separation of $X$ and $Y$ chromosome-bearing spermatozoa by fluorescence-activated cell sorting}

The efficiency of separation of $X$ and $Y$ chromosome-bearing spermatozoa by FACS is shown (Fig. 1). The high fluorescence signal produced when the flattened heads of bull spermatozoa are viewed edge on by the $90^{\circ}$ detector enabled appropriately orientated spermatozoa to be selected for identification as $X$ or $Y$ chromosome-bearing by the $0^{\circ}$ detector. The contours in Fig. 1a show that two peaks can be resolved in this region of high fluorescence with the upper peak resulting from the enhanced fluorescence characteristic of spermatozoa carrying the $X$ chromosome. A histogram of the signals from the $90^{\circ}$ detector (Fig. Ib) shows these overlapping populations more clearly, together with the positioning of the electronic 'gates', which restricted collection of spermatozoa to the most widely separated edges of the populations. Re-analysis of sorted sperm populations was used to check the efficiency of sorting, and enrichment of between $70 \%$ and $80 \%$ was achieved

\section{Assessment of variation among bulls in sperm proteins analysed by SDS-PAGE}

Detergent-extracted proteins prepared from ejaculated spermatozoa from four different bulls, separated by nonreducing SDS-PAGE and stained with Coomassie blue, showed no differences in protein profile among bulls (data not shown). Similarly, protein profiles of spermatozoa from the rete testis or the cauda epididymides of a number of bulls were comparable within each region. On the basis of these results, it was thought unnecessary to use the same bull for all screening procedures so sperm protein extracts from nine individuals were used to prepare western blots for antibody screening. Two bulls consistently produced semen containing a high percentage ( $>75 \%$ ) of motile spermatozoa, and semen from these animals was used for FACS-sorting.

\section{Radiolabelling of sperm proteins}

The profiles of ${ }^{125} \mathrm{I}$-labelled sperm proteins varied depending upon the method of iodination us.ed (Figs 2 and 3). Bolton and 


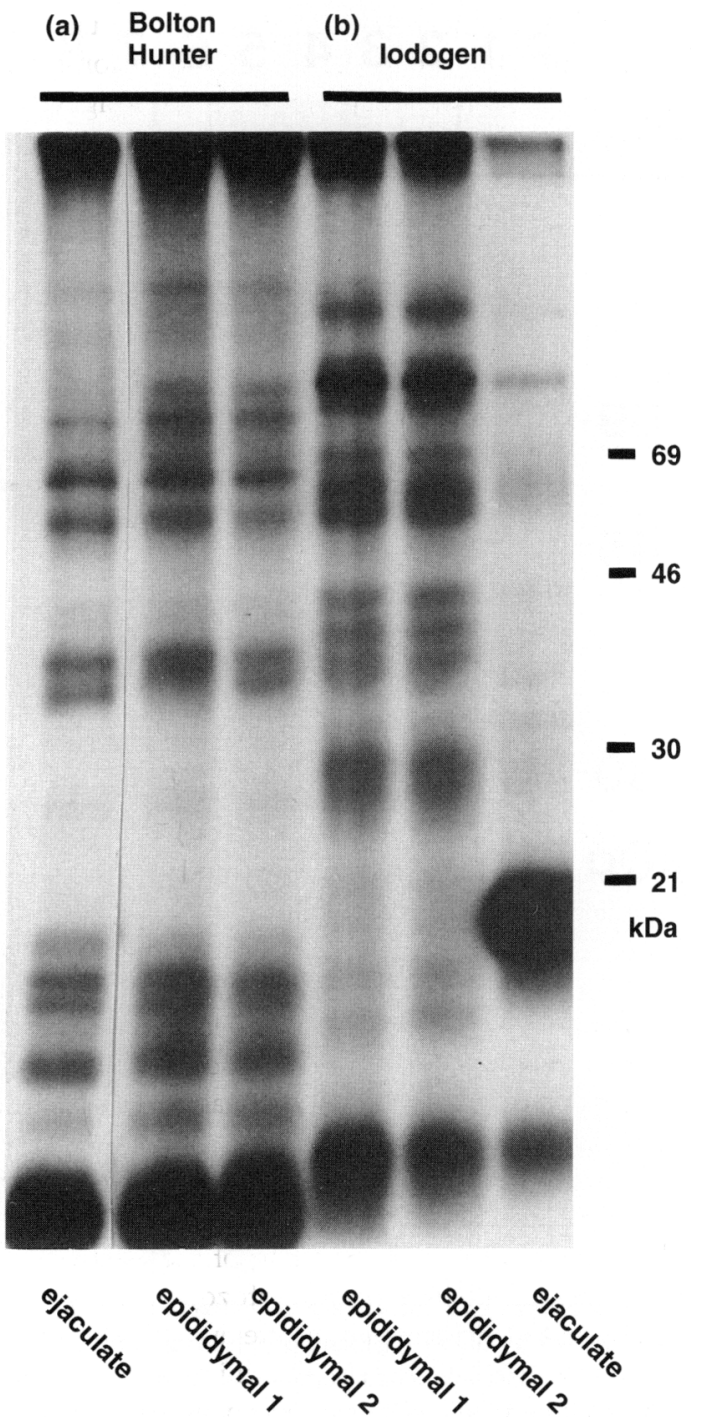

Fig. 2. Autoradiograph of sperm proteins radiolabelled with $\left[{ }^{125} \mathrm{I}\right]$ using (a) permeant Bolton and Hunter reagent and (b) surface labelling Iodogen reagent separated by SDS-PAGE. Both ejaculated and cauda epididymidal sperm proteins show similar profiles with Bolton and Hunter reagent, but lodogen gives heavy labelling of a seminal plasma protein (about $20 \mathrm{kDa}$ ) on ejaculated spermatozoa. The pattern of labelling of proteins from epididymidal spermatozoa differs between the two reagents with increased labelling of low molecular mass proteins with Bolton and Hunter reagent. Relative molecular mass is indicated in $\mathrm{kDa}$.

Hunter reagent, which is a permeant compound, labelled proteins with a wide range of $M_{\mathrm{r}}$ values and showed strong labelling of a number of components of low molecular mass $(<20 \mathrm{kDa})$ from both ejaculated and epididymidal spermatozoa (Fig. 2). The Iodogen and lactoperoxidase techniques, which restrict radiolabelling to proteins at the cell surface, resulted in very heavy labelling of a group of seminal plasma proteins at $18-20 \mathrm{kDa}$ which tended to dominate autoradiographs of gels of ejaculated spermatozoa and obscure more weakly labelled protein bands (Fig. 2, lane 6). The association of radioactivity with a whole range of proteins after lodogen treatment can, therefore, be seen more easily in extracts from (a)

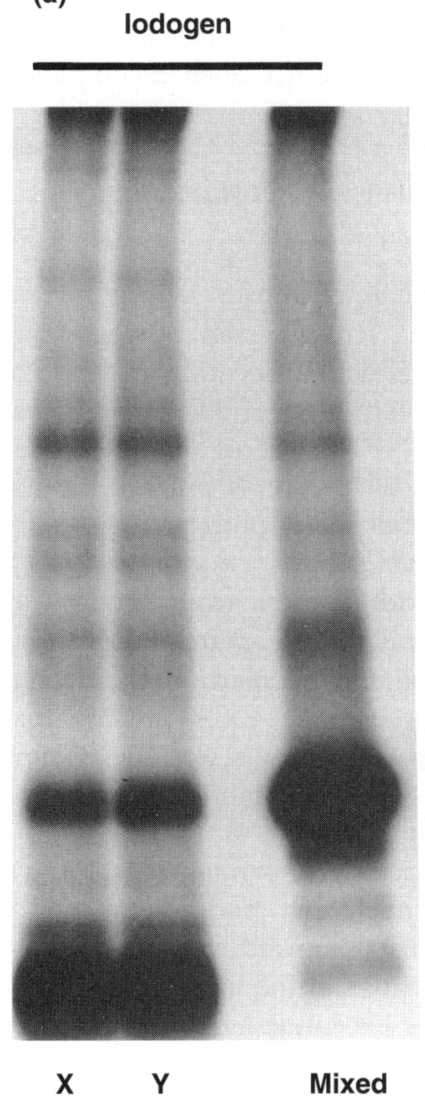

(b) Lactoperoxidase

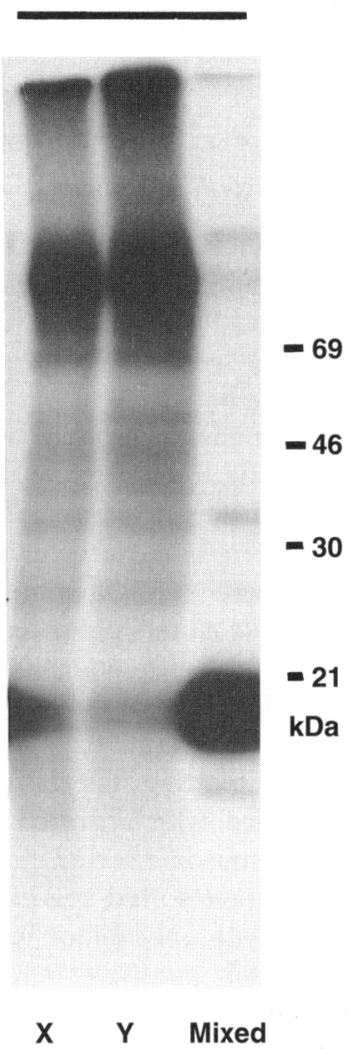

Fig. 3. Autoradiograph comparing surface protein profiles of FACSsorted and unsorted ejaculated spermatozoa radiolabelled using (a) Iodogen reagent or (b) lactoperoxidase. Extracts of both $X$ and $Y$ chromosome-bearing spermatozoa have identical profiles and differ from unsorted spermatozoa only in the reduced presence of a heavily labelled protein of about $20 \mathrm{kDa}$ derived from seminal plasma. This band is so predominant in the lactoperoxidase labelled unsorted sperm extract that other labelled proteins are underexposed. Relative molecular mass indicated in $\mathrm{kDa}$.

epididymidal spermatozoa, which are free of seminal plasma (Fig. 2). Since the epididymidal proteins shown (Fig. 2) come from two different bulls, this serves to illustrate the similarity in protein profiles between individuals previously noted for preparations stained with Coomassie blue.

Both methods of surface labelling resulted in identical profiles for the $X$ and $Y$ chromosome-enriched populations of ejaculated spermatozoa after FACS separation (Fig. 3). However, a comparison of the three tracks in Fig. 3a shows that the sorted populations differ from unsorted spermatozoa both in weaker labelling of the $18-20 \mathrm{kDa}$ seminal plasma bands and heavy labelling of low molecular mass components, reminiscent of the labelling seen with Bolton and Hunter reagent (Fig. 2). This observation suggests that the sorting process modifies the sperm surface membrane in two respects; first, it removes loosely bound components; and second, it may cause sufficient membrane damage to permeabilize the cells and expose internal proteins to the Iodogen labelling process. Iodination with lactoperoxidase also failed to reveal any differences between sorted sperm populations (Fig. $3 \mathrm{~b}$ ) and, in the example 
illustrated, the very large amounts of labelling associated with the seminal plasma proteins on unsorted spermatozoa again resulted in under-exposure of most other labelled components.

\section{Presence of sex-specific antigens on spermatozoa assessed by immunological techniques}

Antisera screening. Individual responses to the different immunization protocols used were assessed by removing a blood sample from each rat after the boosting injection and using the serum to probe western blots of bull sperm proteins separated by non-reducing SDS-PAGE. Most animals showed a strong immune response and all protocols produced antisera that bound to a spectrum of bull sperm proteins ranging from approximately $15 \mathrm{kDa}$ to $200 \mathrm{kDa}$.

Western blots screened with antisera from group 1 rats immunized with different numbers of spermatozoa showed that, while all rats produced an immune reaction, the strongest response was in animals receiving $>4 \times 10^{6}$ spermatozoa. Therefore, in subsequent experiments this was the minimum number of spermatozoa used for immunization. Preliminary western blotting results using antisera from six rats (two immunized with unsorted ejaculated spermatozoa, two with $X$ chromosome-sorted spermatozoa and two with $Y$ chromosome-sorted spermatozoa) showed similar reactions in all rats with only minor variations in the intensity of reaction over certain constituents. One exception to this was a protein of about $50 \mathrm{kDa}$ detected on all blots except those tested with antisera from rats immunized with $X$ chromosome-sorted spermatozoa (data not shown). Two groups of eight rats were identically immunized with either $X$ or $Y$ chromosome-enriched spermatozoa as antigen to establish whether this reflected a real difference in immunogenicity of $X$ chromosome-bearing spermatozoa or resulted from variation in immune response between animals. The first group was injected with sorted spermatozoa derived from ejaculates and the second with sorted spermatozoa from the cauda epididymidis. Results from all 16 animals were comparable. A western blot probed with antisera from the first group showed a considerable degree of similarity between the proteins detected by all eight antisera, again with minor variations, and the protein of about $50 \mathrm{kDa}$ appeared with differing degrees of clarity in all lanes except lane 6 (Fig. 4). Other small variations that occurred between individuals were never associated consistently with either $X$ or $Y$ chromosome-bearing spermatozoa and no antigenic differences between the two types were detected at this level of analysis.

Binding of antibodies to $X$ and $Y$ chromosome-bearing spermatozoa and detergent-extracted sperm proteins separated by SDS-PAGE, Hybridoma supernatants containing anti-sperm immunoglobulins were screened initially using IIF to assess their ability to bind to bull spermatozoa. When antibodies were identified, individual hybridoma cells were cloned and a panel of monoclonal antibodies (mAbs) to a wide range of sperm antigens found on ejaculated, cauda epididymidal and testicular spermatozoa was formed. Many of the mAbs recognized antigens whose distribution was limited to distinct regions of the spermatozoa (the acrosome, postacrosome and equatorial
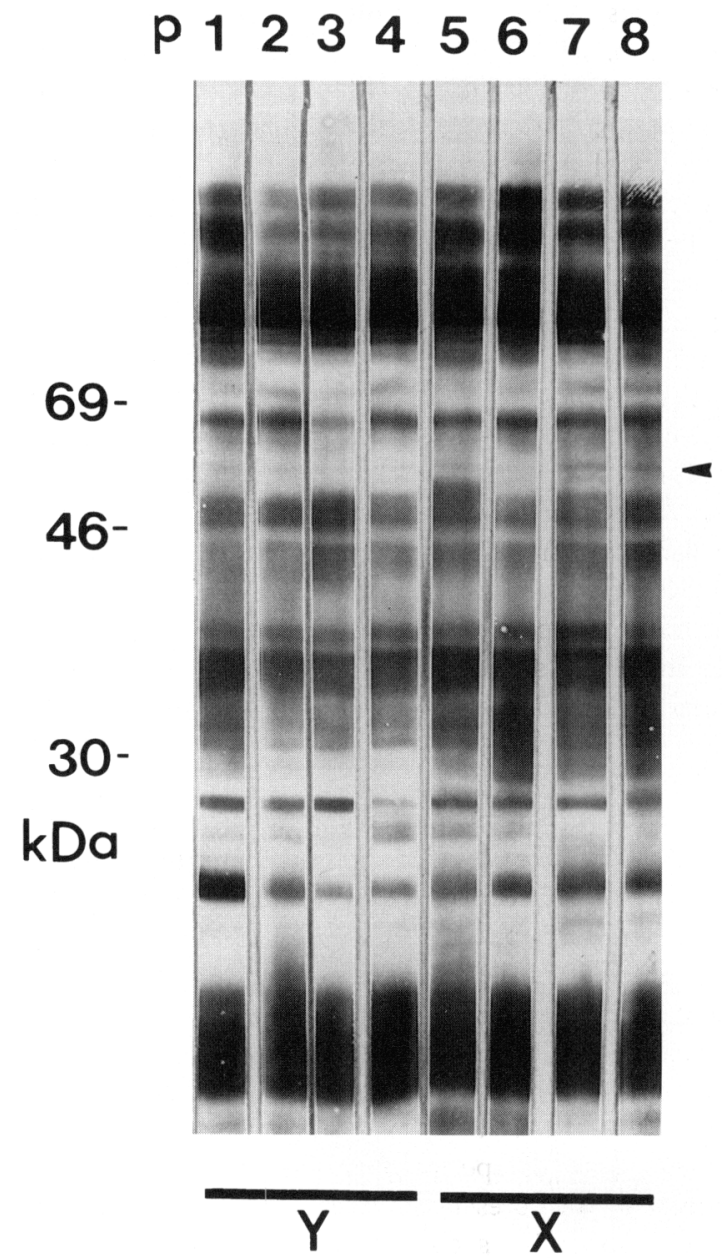

Fig. 4. A western blot of detergent-extracted ejaculated sperm proteins separated by SDS-PAGE and probed with antisera from eight rats injected with FACS-enriched populations of $X$ or $Y$ chromosomebearing spermatozoa. No consistent differences between populations were detected. A protein of about $50 \mathrm{kDa}$ (arrowhead), thought from initial experiments to be $Y$ chromosome-specific, was detected by sera from both groups of animals. Lanes 1-4, antisera from rats injected with $Y$ chromosome-bearing spermatozoa; lanes 5-8, antisera from rats immunized with $X$ chromosome-bearing spermatozoa; $\mathrm{p}$, pre-immune serum. Relative molecular mass indicated in $\mathrm{kDa}$.

segment of the head or the midpiece and principal piece of the tail) while others had a more widespread distribution. In all, 15 distinctive labelling patterns could be recognized using antibodies to ejaculated and epididymidal spermatozoa, while only eight of these were identified during the screening of antibodies to testicular spermatozoa. This finding suggests that the maturational changes occurring as spermatozoa pass through the epididymis are accompanied by an increase in sperm antigenicity.

The sperm antigens recognized by different antibodies were identified by screening supernatants from positive hybridomas on western blots of detergent-solubilized sperm proteins separated by SDS-PAGE. A high proportion of the antibodies raised against ejaculated spermatozoa associated with low molecular mass proteins $(<25 \mathrm{kDa})$. Thus, from a typical fusion, $42 \%$ of the supernatant antibodies reacting with 
western blots bound to a variety of proteins between $25 \mathrm{kDa}$ and $100 \mathrm{kDa}$, while $58 \%$ bound to just two protein bands at about $18 \mathrm{kDa}$ and $20 \mathrm{kDa}$. These latter proteins derive from seminal plasma and are present on all ejaculated spermatozoa; they are closely associated with the sperm surface and are not readily removed by washing. The presence of such highly antigenic proteins may mask other, less abundant surface proteins and reduce the likelihood of an immune response being mounted against them. Identical protein blots, probed with antibodies from rats immunized with cauda epididymidal or testicular spermatozoa, which have no seminal plasma component, showed a reduction in the number of antibodies recognizing low molecular mass components. In a typical fusion, $70 \%$ of antibodies reacted with a variety of higher molecular mass bands and only $30 \%$ reacted with proteins at or below $20 \mathrm{kDa}$.

The extensive panel of mAbs to bull spermatozoa selected during the initial screening process was reviewed to identify potential sex-specific mAbs. On the assumption that equal numbers of $X$ and $Y$ chromosome-bearing spermatozoa are present in semen, $163 \mathrm{mAbs}$ recognizing about $50 \%$ of spermatozoa in unsorted smear preparations were identified. When these mAbs were re-tested on smears of sorted spermatozoa, 32 of them bound to a similar proportion (between $40 \%$ and $65 \%$ ) of spermatozoa in both the $X$ and $Y$ chromosomeenriched samples, while the remaining 131 bound to almost all ( $>90 \%$ ) spermatozoa in both samples. One explanation of these results is that the first group of mAbs, which binds to approximately half the spermatozoa in both sorted and unsorted preparations, associates with surface antigens that are not present on all spermatozoa but whose distribution is unrelated to the presence of either sex chromosome. In contrast, $m A$ bs in the second group, where binding to both $X$ and $Y$ chromosome-bearing spermatozoa is greatly increased after sorting, probably recognize internal antigens that are rendered more accessible by the combined processes of flow cytometry and smear preparation. Evidence to support this interpretation was obtained using an antibody, MAC 396 , known to bind to an internal antigen. Spermatozoa were labelled in suspension (i) after washing, (ii) after permeabilization by cold-shock (achieved by rapid cooling of washed spermatozoa to $4^{\circ} \mathrm{C}$ followed by a return to $30^{\circ} \mathrm{C}$ and a repeat of the cooling process) and (iii) after FACS sorting. Only $23 \pm 4.5 \%$ (mean \pm SEM, $n=3$ ) of washed spermatozoa bound MAC 396, but this increased to $97 \pm 2.5 \%(n=3)$ after cold shock. An intermediate figure of $59 \pm 2.1 \%(n=6)$ was obtained for FACS-sorted spermatozoa, which was indicative of a considerable degree of permeabilization during sorting.

\section{High resolution two-dimensional SDS-PAGE}

Since differences in sperm surface proteins between $X$ and $Y$ chromosome-enriched populations could not be demonstrated either by immunological means or by using one-dimensional SDS-PAGE, a more detailed comparison of the proteins present in each population was carried out using two-dimensional SDS-PAGE. In this case, lysis buffer was used to make extracts of FACS-sorted spermatozoa so that both surface and internal proteins were included in the analysis. In analysing the paired gels of $\mathrm{X}$ or $\mathrm{Y}$ chromosome-derived proteins in each experiment, emphasis was placed on detecting any protein that was consistently present on only one gel in each pair. Smaller quantitative differences that might occur between the gels would not be detected by this method of analysis. Between 234 and 351 protein 'spots' could be resolved by eye, depending on the amount of protein loaded. A spot-by-spot comparison of the protein separations on the $X$ and the $Y$ chromosome-enriched gels showed a close correspondence between the two (Fig. 5a, b) However, in one region a difference was detected, with the presence of a small cluster of proteins ( $\mathrm{pI}$ about 5.3; molecular mass about $40 \mathrm{kDa}$ ) that was unique to the $X$ chromosome-enriched gel (Fig. $5 \mathrm{c}, \mathrm{d}$ ). This group was present on all three of the $X$ chromosome-enriched gels but was not detected on any of the $Y$ chromosomeenriched samples, even when the $Y$ chromosome-enriched sample was more heavily loaded with protein (Fig. 5), thus biasing the system against the appearance of $X$ chromosomespecific proteins. Protein extracts from unsorted spermatozoa and from an unsorted sample enriched with plasma membrane vesicles were run in parallel with the sorted extracts in two experiments. The whole sperm extract gave a virtually identical pattern of protein distribution to that seen in the sorted sperm extracts and a very faint area of silver staining was observed in the $40 \mathrm{kDa}, 5.3 \mathrm{pl}$ area of the gel corresponding to the group of proteins of about $40 \mathrm{kDa}$ seen on the $X$ chromosomeenriched gel. Thus, a protein component present in samples containing about $80 \%$ of $X$ chromosome-bearing spermatozoa was just detectable in unsorted samples where the proportion of $X$ chromosome-bearing spermatozoa would be expected to be $50 \%$, but was not seen when the proportion of $X$ chromosome-bearing spermatozoa in a sample was reduced to about $20 \%$. The two-dimensional distribution pattern of proteins in the membrane-enriched sample differed from that of the whole sperm extracts, and no component corresponding to the $X$ chromosome-specific group could be detected, which suggested that it was not a surface membrane protein.

\section{Discussion}

The presence of an antigen capable of distinguishing between $X$ and $Y$ chromosome-bearing spermatozoa depends upon two suppositions: (i) that expression of genes associated with, or controlled by, the sex chromosomes occurs in haploid spermatids; and (ii) that the gene product is confined to the spermatozoa carrying that chromosome. Although the sex chromosomes have generally been regarded as inactivated by the pachytene stage of meiotic prophase (Handel, 1987), there is increasing evidence for post-meiotic transcription of genes on both chromosomes. Genes on the $Y$ chromosome expressed in post-meiotic spermatids include $Z f y-1$ and $Z f_{y}$-2 (Nagamine et al., 1990) and Sry (Capel et al., 1993), as well as Y353/B, a DNA sequence on the long arm of the mouse $Y$ chromosome (Conway et al., 1994). Two $X$ chromosome-associated genes, Ube1x and MHR6A, also show pronounced post-meiotic expression (Hendriksen et al., 1995) and there is evidence that the Hprt gene remains active during spermatogenesis (Shannon and Handel, 1993). However, while these results confirm that transcripts associated exclusively with either $X$ or $Y$ 

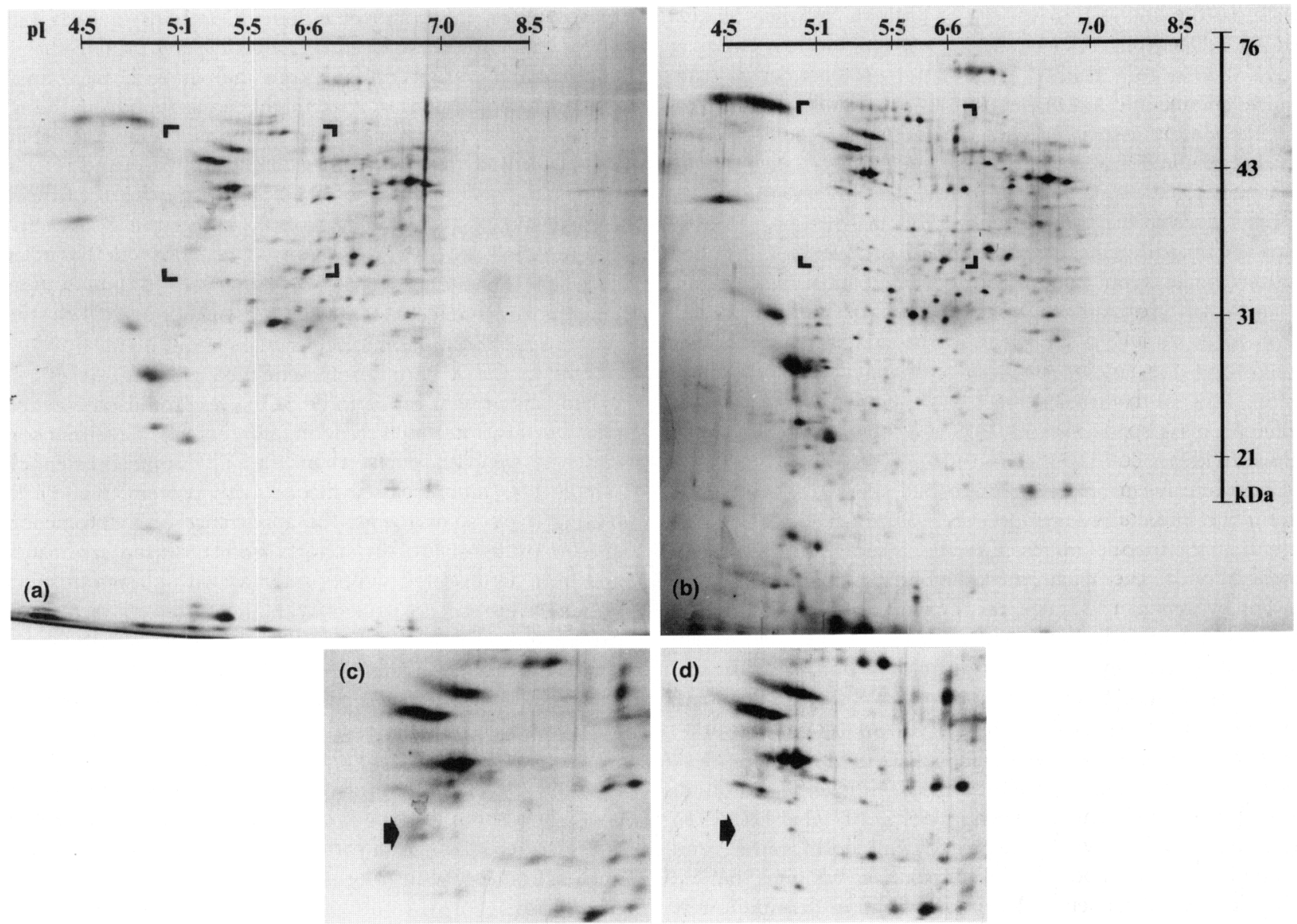

Fig. 5. Proteins extracted from FACS-separated sperm populations separated by two-dimensional gel electrophoresis and visualized by silver staining. The gel of proteins from predominantly $X$ chromosome-bearing spermatozoa (a) is less heavily loaded than the gel of $Y$ chromosome-bearing spermatozoa (b) but, nevertheless, a comparison of protein 'spots' appearing on the $X$ chromosome-enriched gel shows that they all have a counterpart on the $Y$ chromosome-enriched gel, with the exception of a group of proteins (pI about 5.3, molecular mass about $40 \mathrm{kDa}$ ) within the regions marked on (a) and (b) and enlarged in (c) and (d), respectively. The area of $X$ chromosome-enriched gel shown in (c) contains a group of proteins (arrow) absent from the equivalent area of the $Y$ chromosome-enriched gel arrowed in (d).

chromosome-bearing spermatozoa occur, they may transfer between neighbouring cells by way of the cytoplasmic bridges that link post-meiotic spermatids and become universally distributed (Braun et al., 1989; Caldwell and Handel, 1991).

The present study was designed to look for differences between populations of bovine spermatozoa sorted by FACS by (i) comparing both their surface and intracellular protein complements, and (ii) generating $\mathrm{mAbs}$ to a wide range of sperm antigens and assessing their binding to sorted spermatozoa. The first approach is hampered by the very small number of sorted spermatozoa available for analysis. For comparing the surface proteins present in sorted populations, radiolabelling techniques were necessary to allow highly sensitive monitoring of iodinated surface proteins. While separation of iodinated proteins extracted with non-ionic detergents by one-dimensional SDS-PAGE gave identical protein profiles for both sorted populations, it should be borne in mind that only a proportion of surface proteins (specifically those containing exposed tyrosine residues, although histidines and tryptophans are also available for iodination) will be labelled by these methods and the relative amounts of $\left[{ }^{125} \mathrm{I}\right]$ incorporated may not reflect the absolute quantity of protein present. The possibility remains, therefore, of differences between the populations of $X$ and $Y$ chromsome-bearing spermatozoa either in proteins unlabelled by the iodination process or in proteins of low abundance.

Having failed to identify any differences in surface proteins, we separated whole sperm lysates by two-dimensional SDSPAGE to obtain as complete a picture as possible of the protein complement of the two populations. In this case, a protein cluster specific to the gel of $\mathrm{X}$ chromosome-enriched spermatozoa was identified. Three such analyses were carried out with each sample consisting of spermatozoa from between 12 and 19 ejaculates taken from three different bulls. Our results indicate that the $X$ chromosome-specific protein is present consistently in different samples of semen. Its absence from a plasma membrane-enriched preparation suggests that it is intracellular and is, therefore, unlikely to provide a useful marker for sex selection of live spermatozoa. There may be additional differences in protein content between the two populations but these are unlikely to be revealed unless sufficient sorted material is collected to provide a complete 
profile of the sperm proteins present in each population that can be subjected to quantitative analysis. This approach has been used to examine $X$ and $Y$ chromosome-enriched samples of boar spermatozoa but no consistent differences between the two populations could be detected (Hendriksen et al., 1996). Even if very large numbers of sorted spermatozoa are accrued, a number of lines of evidence suggest that there is loss of surface membrane components during the sorting process. Thus, radiolabelling studies show both a reduction in seminal plasma proteins associated with the sperm membrane and exposure of internal proteins through changes in membrane permeability to iodinating agents, while antibody studies have shown that the surface membrane of sorted spermatozoa is more permeant than that of unsorted spermatozoa. Membrane damage during sorting might be reduced by using BSA in the sheath fluid, by collecting into a protein-rich medium and by the addition of seminal plasma (Maxwell et al., 1997) but even with these measures in place, our experience suggests that sorted spermatozoa are more fragile than unsorted ones. The modification of the sperm surface suggested by these observations may mean that no analysis of sorted spermatozoa will reflect all the proteins originally present at the surface membrane accurately.

Perhaps the most sensitive probe for detecting differences between cells is the immune response and claims have been made of antibodies able to distinguish between $X$ and $Y$ chromosome-bearing spermatozoa. We have tested populations of $X$ and $Y$ chromosome-bearing bovine spermatozoa separated by FACS with a panel of $\mathrm{mAbs}$ that initially were found to bind to about $50 \%$ of spermatozoa in unsorted preparations. Subsequently, however, none of the antibodies showed specificity to either $X$ or $Y$ chromosome-bearing spermatozoa. In most cases the initial observation could be explained on the basis of differential access of the antibody to an intracellular antigen, dependent upon the integrity of the sperm surface membrane, but a few examples of antibodies to surface membrane-associated proteins consistently showed differential binding that was unrelated either to membrane permeability or to the possession of an $X$ or $Y$ chromosome. This indication of heterogeneity at the sperm surface, independent of the presence of a particular sex chromosome, emphasizes the need for caution in interpreting the results of antibody binding experiments. When an antibody consistently binds to about $50 \%$ of the sperm population, it is tempting to associate this with recognition of $X$ or $Y$ chromosome-bearing spermatozoa. However, only by checking antibody associations with sperm populations separated by FACS can such a link be demonstrated reliably. This is borne out by studies of one candidate immunological marker, the $\mathrm{H}-\mathrm{Y}$ antigen, which is found exclusively in male mammalian tissues (Wachtel et al., 1975). A number of researchers have shown that antibodies to $H-Y$ bind only a proportion of the sperm population, and it has been postulated that these are spermatozoa carrying a $Y$ chromosome. Attempts to prove this hypothesis have led to conflicting results; while some studies have indicated that treatment with antiserum to $\mathrm{H}-\mathrm{Y}$ before fertilization biases the sex ratio of embryos (Bennett and Boyse, 1973; Zavos, 1983) or have suggested a correlation between anti-H-Y antibody binding and the presence of the $Y$ chromosome (Ali et al., 1990), others have found no evidence of a linkage between the two (Ohno and Wachtel, 1978; Hoppe and Koo, 1984). The advent of the FACS sorting technique enabled Hendriksen et al. (1993) to carry out a study of the binding characteristics of seven anti-H-Y antibodies to bovine and porcine spermatozoa sorted by this technique and they concluded that, although antibodies did not bind to all spermatozoa, they showed no preferential association with $Y$ chromosome-bearing spermatozoa.

Although a sex-specific surface antigen was not identified in the present study, this does not prove that such a marker is absent. The results do suggest, however, that if an antigen is present, it is a minor component of the membrane with a low antigenicity, and that an immunological approach to sperm sexing is unlikely to prove fruitful unless a gene product exclusive to one of the sex chromosomes can be identified and isolated. High resolution two-dimensional SDS-PAGE is one route by which such an antigen can be sought. Preliminary results indicate at least one sex-linked difference in protein expression of spermatozoa, and further work with this technique may identify other distinctions between $X$ and $Y$ chromosome-bearing spermatozoa. Another approach may be based on the recent finding that $\mathrm{H}-\mathrm{Y}$ expression is linked to the $S M C$ gene sited on the $Y$ chromosome. Two regions showing substantial differences from the $X$ chromosome homologue, $S M C X$, and coding for peptides unique to the $Y$ chromosome have been identified (Scott et al., 1995; Wang et al., 1995). Such information should enable $Y$ chromosome-specific peptide antibodies to be produced which may be capable of differentiating between types of spermatozoa, although current evidence indicates that $\mathrm{H}-\mathrm{Y}$ antigens are unlikely to be associated with the cell surface.

The authors thank L. Richardson for her help in the early stages of monoclonal antibody production and J. Lury and D. Ruffel for technical assistance. They are grateful to Genus for providing bull semen. This work was funded by. a grant from the Milk Marketing Board.

\section{References}

Ali JI, Eldridge FE, Koo GC and Schanbacher BD (1990) Enrichment of bovine $X$ - and Y-chromosome-bearing sperm with monoclonal H-Y antibodyfluorescence-activated cell sorter Archives of Andrology 24 235-245

Barlow P and Vosa CG (1970) The Y-chromosome in human spermatozoa Nature 226 961-962

Bazin H (1982) Production of rat monoclonal antibodies with the LOU rat non secreting IR983F myeloma cell line Protocols in Biological Fluids 29 615-618

Beernink FJ, Dmowski WP and Ericsson RJ (1993) Sex preselection through albumin separation of sperm Fertility and Sterility 59 382-386

Bennett D and Boyse EA (I973) Sex ratio in progeny of mice inseminated with sperm treated with H-Y antiserum Nature 246 308-309

Bolton AE and Hunter WM (1973) The labelling of proteins to high specific activities by conjugation to a ${ }^{125} \mathrm{I}$-containing acylating agent. Application to the radioimmunoassay Biochemical Journal 133 529-539

Braun RE, Behringer RR, Peschon JJ, Brinster RL and Palmiter RD (1989) Genetically haploid spermatids are phenotypically diploid Nature $\mathbf{3 3 7}$ 373-376

Bradford MM (1976) A rapid and sensitive method for the quantitation of microgram quantities of protein using the principle of protein-dye binding Analytical Biochemistry 72 248-254

Caldwell KA and Handel MA (1991) Protamine transcript sharing among postmeiotic spermatids Proceedings of the National Academy of Science USA $\mathbf{8 8}$ $2407-2410$ 
Capel B, Swain B, Nicolis S, Hacker A, Walter M, Koopman P, Goodfellow P and Lovell-Badge $\mathbf{R}$ (1993) Circular transcripts of the testis-determining gene Sry in adult mouse testis Cell 73 1019-1030

Conway SJ, Mahadevaiah SK, Darling SM, Capel B, Rattigan AM and Burgoyne PS (1994) Y353/B: a candidate multiple copy spermiogenesis gene on the mouse $Y$ chromosome Mammalian Genome 5 203-210

Cran DG, Johnson LA, Miller NGA, Cochrane D and Polge C (1993) Production of bovine calves following separation of $\mathrm{X}$ - and $\mathrm{Y}$-chromosome bearing sperm and in vitro fertilization Veterinary Record 132 40-41

David GS and Reisfeld RA (1974) Protein iodination with solid state lactoperoxidase Biochemistry 13 1014-1021

Ericsson RJ, Langevin CN and Nishino M (1973) Isolation of fractions rich in human $Y$ sperm Nature $246421-424$

Galfre G and Milstein C (1981) Preparation of monoclonal antibodies: strategies and procedures Methods in Enzymology 73 13-46

Galfre G, Milstein C and Wright B (1979) Rat $\times$ rat hybrid myelomas and a monoclonal anti-Fd portion of mouse IgG Nature 277 131-133

Gaunt SJ, Brown CR and Jones R (1983) Identification of mobile and fixed antigens on the plasma membrane of rat spermatozoa using monoclonal antibodies Experimental Cell Research 144 275-284

Goldberg EH, Boyse FA, Bennet D, Scheid M and Carswell EA (1971) Serological demonstration of $\mathrm{H}-\mathrm{Y}$ (male) antigen in mouse sperm Nature 232 478-480

Handel MA (1987) Genetic control of spermatogenesis in mice. In Spermatogenesis: Genetic Aspects. Results and Problems in Cell Differentiation. Vol. 15 pp 1-62 Ed. W Hennig. Springer-Verlag, Berlin, Heidelberg, New York

Harvey EN (1946) Can the sex of mammalian offspring be controlled? Journal of Heredity 37 71-73

Hendriksen PJM, Tieman M, van der Lende $T$ and Johnson LA (1993) Binding of anti- $\mathrm{H}-\mathrm{Y}$ monoclonal antibodies to separated $X$ and $Y$ chromosome bearing porcine and bovine sperm Molecular Reproduction and Development 35 189-196

Hendriksen PJM, Hoogerbrugge JW, Themmen APN, Koken MHM, Hoeijmakers JHJ, Oostra BA, van der Lende T and Grootegoed JA (1995) Postmeiotic transcription of $X$ and $Y$ chromosomal genes during spermatogenesis in the mouse Developmental Biology 170 730-733

Hendriksen PJM, Welch GR, Grootegoed JA, van der Lende T and Johnson LA (1996) Comparison of detergent-solubilized membrane and soluble-proteins from flow cytometrically sorted $X$-chromosome and $Y$-chromosome bearing porcine spermatozoa by high resolution 2-D electrophoresis Molecular Reproduction and Development $45 \quad 342-350$

Hoppe PC and Koo GC \{1984) Reacting mouse sperm with monoclonal H-Y antibodies does not influence the sex ratio of eggs fertilized in vitro. Journal of Reproductive Immunology 6 1-9

Johnson LA \{1988\} Flow cytometric determination of sperm sex ratio in semen purportedly enriched for $X$ or $Y$ bearing sperm Theriogenology 29265

Johnson LA (1992) Gender preselection in domestic animals using flow cytometrically sorted sperm Journal of Animal Science 70 (Supplement 2) 8-18

Johnson LA and Pinkel D (1986) Modifications of a laser-based flow cytometer for high resolution DNA analysis of mammalian spermatozoa Cytometry 7 268-273

Johnson LA, Flook JP and Hawk HW (1989) Sex preselection in rabbits: live births from $X$ and $Y$ sperm separated by DNA and cell sorting Biology of Reproduction 41 199-203

Johnson LA, Welch GR, Keyvanfar K, Dorfmann A, Fugger EF and Schulman JD (1993) Gender preselection in humans? Flow cytometric separation of $X$ and $\mathrm{Y}$ spermatozoa for the prevention of $\mathrm{X}$-linked diseases Human Reproduction $81733-1739$

Jones R (1986) Preparation of a plasma membrane-rich fraction from rat spermatozoa Journal of Reproduction and Fertility 77 435-449
Jones R, von Glos KI and Brown CR (1983) Changes in the protein composition of rat spermatozoa during maturation in the epididymis Journal of Reproduction and Fertility 67 299-306

Kaneko S, Oshio S, Kobayashi T, Izuka R and Mohri H (1984) Human X-and $Y$-bearing sperm differ in cell surface sialic acid content Biochemical and Biophysical Research Communications 124 950-955

Laemmli UK (1970) Cleavage of structural proteins during the assembly of the head of bacteriophage T4 Nature 227 680-685

Levinson G, Keyvanfar K, Wu JC, Fugger EF, Fields RA, Harton GL, Palmer FT, Sisson ME, Starr KM, Dennison-Lagos L, Calvo L, Sherins RJ, Bick D, Schulman JD and Black SH (1995) DNA-based X-enriched sperm separation as an adjunct to preimplantation genetic testing for the prevention of X-linked disease Molecular Human Reproduction 10 979-982

McNutt TL and Johnson LA (1996) Flow cytometric sorting of sperm: influence on fertilization and embryo/fetal development in the rabbit Molecular Reproduction and Development $43261-267$

Markwell MK and Fox CF (1978) Surface-specific iodination of membrane proteins of viruses and eucaryotic cells using 1,3,4,6-tetrachloro-3a,6 -diphenylglycoluril Biochemistry 17 4807-4817

Maxwell WMC, Welch GR and Johnson LA (1997) Viability and membrane integrity of spermatozoa after dilution and flow cytometric sorting in the presence or absence of seminal plasma Reproduction, Fertility and Development 8 1165-1178

Morrissey JH (1981) Silver stains for proteins in polyacrylamide gels: a modified procedure with enhanced uniform sensitivity Analytical Biochemistry $117307-310$

Nagamine CM, Chan K, Hake LE and Lau YC (1990) The two candidate testis-determining $Y$ genes $\left(Z f_{y-1}\right.$ and $\left.Z f y-2\right)$ are differentially expressed in fetal and adult mouse tissues Genes and Development 4 63-74

Ohno $S$ and Wachtel SS (1978) On the selective elimination of $Y$ bearing sperm Immunogenetics 7 13-16

Pearson PL and Bobrow M (1970) Fluorescent staining of the $Y$ chromosome in meiotic stages of the human male Journal of Reproduction and Fertility $\mathbf{2 2}$ 177-179

Scott DM, Ehrman IE, Ellis PS, Bishop CE, Agulnik AI, Simpson E and Mitchell MJ (1995) Identification of a mouse male-specific transplantation antigen, $\mathrm{H}-\mathrm{Y}$ Nature 376 695-698

Shannon M and Handel MA (1993) Expression of the Hprt gene during spermatogenesis: implications for sex-chromosome inactivation Biology of Reproduction 49 770-778

Sumner AT and Robinson JA (1976) A difference in dry mass between the heads of $X$ - and $Y$-bearing human spermatozoa Journal of Reproduction and Fertility 48 9-15

Wachtel SS, Koo GC and Boyse EA (1975) Evolutionary conservation of H-Y (male) antigen Nature 254 270-272

Wang W, Meadows LR, den Haan JMM, Sherman NE, Chen $Y$, Blokland E, Shabanowitz J, Agulnik AI, Hendrickson RC, Bishop CE, Hunt DF, Goulmy E and Engelhard VH (1995) Human H-Y: a male-specific histocompatibility antigen derived from the SMCY protein Science 269 1588-1590

Welch GR, Waldbeiser GC, Wall RJ and Johnson LA (1995) Flow cytometric sperm sorting and PCR to confirm separation of X-and Y- chromosome bearing bovine sperm Animal Biotechnology 6 131-139

Windsor DP, Evans G and White IG (1993) Sex predetermination by separation of $X$ and $Y$ chromosome-bearing sperm: a review Reproduction, Fertility and Development 5 155-171

Zavos PM (1983) Preconception sex determination via intra-vaginal administration of $\mathrm{H}-\mathrm{Y}$ antisera in rabbits Theriogenology 20 235-240 